\title{
Üstün Zekâlıların Eğitiminde Hızlandırma Yönteminin Kullanılması
}

\author{
ADNAN KULAKSIZOĞLU
}

Hepimiz farklı özelliklere sahibiz. Bireye ait özellikler bedensel, duygusal, sosyal, zihinsel, kişisel, ahlaki ve cinsel özellikler başlığı altında toplanabilir. Bu özelliklerimizden zekâmız öğrenme hızımızı, öğrenme miktarını ve genişliğini, öğreneceğimiz bilginin türünü, öğrendiklerimizi akılda tutmayı belirler. Doğuştan getirdiğimiz ve öğrenme yolu ile potansiyelimiz oranında geliştirebileceğimiz zekâ ölçülebilen bir özelliktir.

İnsanların üçte ikilik veya yaklaşık yüzde altmış sekizlik kısmı zekâca "normal" kabul edilir. Bu kesimin zekâ puanı 85 ile 115 arasındadır. Zekâca normal olanların üzerinde kalanlar üstün zekâlı (Ü.Z.) olarak isimlendirilirler. Bunların zekâ puanları ve bunların yaygınlığı aşağıdaki gibidir (Bakioğlu, A. ve Levent, B. 2013).

Hafif Derecede (Ü. Z.)'lılar: Zekâ Bölümü: 115-129, Yaygınlığı: 1:40 Normal (Ü.Z.)'lılar: zekâ Bölümü: 130-144, Yaygınlığı: 1:40, 1:1000 Çok (Ü.Z.)'lılar: zekâ Bölümü: 145-159, Yaygınlığı: 1:1000- 1:10.000 Olağanüstü (Ü.Z.)'lılar: Zekâ Bölümü: 160-179, Yaygınlığı: 1:10000- 1 Milyon Dahi Düzeyinde (Ü.Z.)'lılar: Zekâ Bölümü: 180- ve Üstü, Yaygınlığı: 1: 1 Milyon ve üstü.

Yukarda sıralanan üstün zekâlı (Ü.Z.) grup özel eğitime ihtiyaç duyan, özel olarak yetiştirildiğinde öğrenme hızları çok yüksek olduğu için potansiyellerini en iyi şekilde ortaya çıkarabilen bir kesimdir. Normal öğrencilerle bir arada yetiştirilen Ü.Z.'li öğrencilere sınıflarda işlenen konular basit gelmekte, akademik olarak zorlanmadıkları için de öğrenme

- GÖRÜS-

ADNAN KULAKSIZOĞLU, akulaksizoglu@gmail.com Biruni Üniversitesi Eğitim Fakültesi ORCID: https://orcid.org/0000-0001-9620-0856 doi: https://doi.org/10.47646/CMD.2020.218 
arzuları azalmakta ve okuldan soğumaktadırlar (Chapman, C. Mart, 2009). Bu nedenle üstün zekâlıların eğitiminde onlara uygun gelecek uygulamalardan faydalanmak gerekir.

Üstün zekâlıların eğitiminde uygulanan eğitim yöntemlerini dört ana başlıkta toplayabiliriz (Kanlı, E. 2011-2):

1. Hızlandırma: Öğrenenin hızına göre öğrenmenin uyarlanması.

2. Zenginleştirme: Öğrenilecek içeriğin daha kapsamlı hale getirilmesi.

3. Karmaşıklaştırma: Öğrenilecek konun daha sorut ve karmaşık hale getirilmesi.

4. Yenileştirme: Üstün zekâlılara projeler yaptırarak ve farklı yöntemler kullanarak yeni öğrenme alanlarını öğrenmelerini sağlamak.

Bu makalede hızlandırma yöntemi ve sağlayacağı yararlar üzerinde durulacaktır.

Hızlandırma üstün zekâlıların eğitimi için en kolay, özel eğitilmiş personel ve araç gereç istemeyen, ek bir maddi kaynak gerektirmeyen bir uygulamadır (Ataman, A.2004). Hızlandırma akranlarına göre daha hızlı öğrenen (Ü.Z.)'lilerin zihinsel kapasitelerine, öğrenme hızlarına ve akademik güdülerine uygun şekilde bir programa yerleştirmek ve onların akranlarından önce mezun olmalarını sağlamak amacı ile uygulanan bir yöntemdir. Hızlandırma okuldaki öğrencilerin takvim yaşına göre değil, zihinsel hazırbulunuşluk seviyesine göre sınıflara ayrılmasını ve ona göre eğitim almasını öngören bir uygulamadır (Akarsu, F. 2004).

Hızlandırma ilk olarak A.B.D.'de 1971 yılında uygulanmaya başlamıştır. Bu uygulama üstün zekâlı öğrencilerin lise ve üniversiteye üç yıl ve daha önce girmesini sağlıyorsa bu radikal hızlandırma olarak adlandırılmaktadır (Tortop, H.S. 2012).

Geleneksel uygulamada çocukların yaşla birlikte zihinsel olgunluklarının artacağı ve yedi yaşlarındaki çocukların ilkokul birinci sınıfı başarabilecek zihinsel olgunluğa ulaşacağı kabul edilir. Takvim yaşı her çocuk için zihinsel olgunluğun göstergesi olmaktan uzaktır. Üstün zekâlı çocukların bir kısmı 2-3 yaşlarından itibaren ilk okuma yazma ve aritmetik becerilerini öğrenirken, öğrenme güçlüğü çeken çocuklar da yedi yaşlarından çok sonra ilkokul birinci sınıftaki bilgileri öğrenecek zihinsel olgunluğa ulaşırlar. Kavrama güçleri, öğrenme hızları, öğrenme arzuları, önceden öğrendikleri ve zekâyı oluşturan diğer bütün bileşenleri birbirinden çok farklı olan çocukları 
sırf takvim yaşları birbirine yakın diye aynı sınıfta okumaya mecbur bırakmak eşitlik ilkelerine uymaz (Akarsu, F. 2004). Üstün zekâlıların öğrenme hızları ve öğrenme kapasiteleri yüksektir. Bu çocukların kendilerinden daha yavaş öğrenen akranları ile aynı öğrenme ortamında bulunmaları, onların öğrenme hızlarına göre öğrenmeye mecbur bırakılmaları zihinsel gelişimlerini engelleyebilir,(Çağlar, D. 2004). Bu uygulama (Ü.Z.)'lileri okul yaşamından soğutup uzaklaştırabilir. Oysa (Ü.Z.)'lilerin zihinsel kapasitelerine ve öğrenme hızlarına uygun olarak akademik gelişmelerini sağlamak hep onların kişisel gelişimleri için, hem de ülke menfaatlerine uygundur. (Ü.Z.)'lilerin öğrenme hızlarına ve kapasitelerine uygun olarak daha yoğun öğrenme malzemeleri ile yüzleştirilmeleri ve akranlarından daha hızlı olarak eğitilmeleri ve normal öğrencilerden önce mezun olmaları hızlandırma uygulaması sayesinde mümkündür.

Hızlandırma anaokulu, ilkokul, ortaokul, lise ve üniversitede birçok uygulama biçimine sahiptir.

Dünyanın gelişmiş ülkelerindeki hızlandırma biçimleri aşağıdaki gibidir (Sak, U. Nisan, 2010):

1. Okula Erken Başlama: Okul öncesi dönemdeki üstün zekâlı çocuklar için anaokuluna ve daha sonraki eğitim aşaması olan ilkokula erken başlamak uygun bir uygulamadır.

2. Sınıf Yüikseltme/Atlatma: Öğrencinin takvim yaşının üstünde bir sinıfa yükseltilmesidir.

3. Üniversiteye Erken Başlama: Bu hızlandırma uygulamasında, üstün yetenekli öğrenci liseyi bitirmeden üniversiteyi kazandığı takdirde üniversiteye kayıt olabilir. Lisede vermediği derslerin sınavlarını üniversitedeyken vererek liseyi bitirebilir.

4. Uluslararası Bakalorya Programı (IB): Bu program 3-12 yaşlarına yönelik ilkokul, 11-16 yaşlarına yönelik ortaokul, 16-19 yaşlarına yönelik ortaöğretim (lise) programı olmak üzere üç farklı programdan oluşmaktadır. Ortaöğretim kademesi için sunulan Bakalorya diploma programı üstün zekâlı öğrencilerin eğitimlerinin hızlandırılması için faydalı olabilir.

5. İkili Kayıt: Bu uygulamada lisedeki öğrenciler, liseye devam ederken de üniversiteden ders alabilirler. (Ü.Z.)'lı öğrenciler liseden mezun olup üniversiteye girdikleri zaman aldıkları dersleri kredilerini kullanabilir, böylelikle üniversiteye daha kolay uyum sağlayabilirler ve üniversitedeki dersleri daha erkenden bitirebilirler.

6. Onur Sınıfları: Bu uygulamada öğrenciler lisedeyken diğer üstün zekâlılarla birlikte üniversitedeki onur sınıflarından ders alabilirler. 
7. İleri Yerleştirme Sınıfları: Bu onur sınıfı uygulamasına benzer. Dersler üniversitede değil de liselerde verilir. Bu derslerden alınan krediler üniversitede kullanılır.

8. Üst Sınıflardan Ders Alma: Bu uygulamada 6. sınıftaki bir öğrenci, 7. Sınıftaki bir dersi alabilir ve vaktinden önce dersi geçebilir.

9. Dersin Hızlandırılması: Bu iki yarıyıl devam eden bir dersin bir yarıyılda bitirilebilmesinin mümkün olmasıdır.

10. Sınavla Ders Geçme: Üstün zekâlı öğrencilerin derslere devam etmeden, sınavlara girerek dersi geçme uygulamasıdır. Derslere devam zorunluluğu olmadığından, üst sınıflarda ders alarak geçebilirlerse erkenden okullarını bitirmeleri mümkün olabilir.

\section{Ülkemizde hızlandırma konusundaki uygulamalar}

Milli Eğitim Bakanlığı Okul Öncesi Eğitim ve İlköğretim Kurumları Yönetmeliği'nin 6. maddesinin (a) bendine göre ilkokulların birinci sınıflarına kayıtların yapıldığı yılın Eylül ayı sonu itibariyle 66 ayını dolduran çocukların kaydı yapılır. Yönetmelikte "Gelişim yönünden ilkokula hazır olduğu anlaşılan 60-66 ay arası çocuklardan velisinin yazılı isteği bulunanlar da ilkokul birinci sınıfa kaydedilir" denmektedir (Resmi Gazete, 26 Temmuz 2014, Sayı: 29072). Birinci sınıfa erken kayıt olmak için yazma, resim yapma, kesme yapıştırma gibi el-göz koordinasyonu isteyen becerilerin gelişmiş olmasına bakılır. Kendisinden yaşca büyük olan sınıf arkadaşları ile sosyal ve duygusal olarak birarada olabilecek olgunluğa sahip olması, beden sağlığının iyi olması ve ailesinin çocuğunun okul başarısını ve yükselmesini önemsemesi beklenir (Davaslıgil, Ü. 2004). Hızlandırma konusundaki ikinci uygulama ilgili ilköğretim sınıf mevzuatına göre sadece ilkokulda bir defa olmak üzere sınıf yükseltmektir. Bunun dişında üstün zekâlı bir öğrencinin zekâca üstünlüğü ne olursa olsun sınıf arkadaşlarından önce okulunu bitirme şansı yoktur. Onlarla aynı dersleri aynı dönemde okuyup mezun olmak zorundadır.

Türkiye'de üstün zekâlılar için kapsayıcı, uygulanabilir; ülkemiz ve (Ü.Z.)'liler için yararlı olabilecek kalıcı bir eğitim uygulamamız ne yazık ki yoktur. Bu durum tarihinde Enderun Okulları gibi dünyaya örnek gösterilebilecek bir üstünler okulunu kurarak yüzyıllar boyu işletmiş bir ülkeye yakışan bir durum değildir.

Üstün zekâlıların eğitiminde ülke çapında kapsayıcı ve uygulanabilir bir yöntemin olmamasının birçok nedeni bulunmaktadır.

Bunlardan birincisi ülkemizdeki eğitim politikalarını düzenleyenlerin, eğitim programcılarının, eğitime yön veren kanaat önderlerinin bir kısmının 
(Ü.Z.)'lilerin kim olduklarına, ülkemize ve insanlığa ne tür yararlar sağlıyabileceklerine ilişkin bilgiden yoksun oluşları gelmektedir. İkinci bir engel (Ü.Z.)'lı çocukların ebeveynlerinin örgütsüz olmaları yüzünden, çocuklarının özel eğitimleri ile ilgili olarak Milli Eğitim'den bir hak talep etmemeleri, çocuklarının özel eğitimi ile başbaşa kalmalarıdır. Üstün zekâlı bireylerle hemen hemen aynı oranda bulunan öğrenme güçlüğü çeken ve zekâ engelli çocukların aileleri daha örgütlüdür. Bunun sonucunda çocuklarının eğitimleri ile ilgili yeni haklar talep etmekte ve özel eğitim için ayrılan maddi kaynağın büyük çoğunluğu bu çocuklar için kullanılmaktadır. Üçüncü bir engel (Ü.Z.)'li çocukların normallerle aynı sınıfta, karışık olarak eğitilmeleri gerektiğini düşünen eğitimcilerden gelmektedir (Bakioğlu, A. ve Levent, F. 2013). Eğitimimize yön veren uzmanların önemli bir kısmı üstün zekâlı olanların zaten üstün olduklarını, onlar için özel eğitime ihtiyacın olmadığını düşünmektedir. Dördüncü temel neden üstün zekâlı öğrenciler için uygulanacak özel eğitim sonucu okullarını erken bitiren üstün yeteneklilerin elit bir sınıf oluşturacağı, bunun da topluma zarar vereceği düşüncesidir (Sak, U. Nisan 2010). Halbuki belirli bir alanda özel yeteneği olanlar zaten özel olarak eğitiliyor ve yetenekleri ile sivriliyor. Bu da toplumda sorun oluşturmuyor.

Yukarda sıraladığımız temel nedenler yüzünden ülkemiz eğitim sistemi içinde üstün zekâlıların özel eğitimi ile ilgili bir devlet politikası oluşturulamamıştır.

Üstün zekâlı öğrencilerin hızlı öğrenmeleri, sınıfta öğretmenin öğrettiklerinden tatmin olmamaları, çok soru sormaları, bazı durumlarda öğretmenlerinin ve arkadaşlarının bilgisini küçümsemeleri öğretmenlerini kızdırabilir, öğretmenler üstün zekâlı öğrencileri "sınıfta öğretmenin açığını arayan biri” olarak görebilir (Ataman, A. 27.04.2012). Hiç veya çok az çalıştığı halde ilkokul, ortaokul hatta lisede çok başarılı olan, ama arkadaşları ile olumlu sosyal ilişkiler kuramayan (Ü.Z.)'li çocukların bir kısmı yukardaki nedenlerle okul ortamından soğumakta ve örgün eğitimden ayrılmaktadır.

\section{Hızlandırmanın Sağlayacağı Yararlar}

Hızlandırma sonucu akranlarından önce okullarını bitiren (Ü.Z.)'lılar erken yaşta üniversiteye, erken yaşta yüksek lisansa girebilir veya hayata önceden atılıp bir alanda daha önceden uzmanlık kazanabilir (Tortop, H.S. 2012). En önemlisi eğitim sürecinde harcayacağı zamanı tasarruf ederek, bu kazanımlarını hayata taşıma imkanına sahip olurlar. Hızlandırmanın üstün zekâlılara kazandırdığı duyuşsal özellikler de vardır. Güven duygusundaki 
artış, özsaygılarının gelişmesi, olgunlaşmada ve motivasyonda artış ile sosyal becerilerin gelişmesi kazanımlardan bazılarıdır (Tortop,H.S. 2012).

Hızlandırma eğitimine katılan ve katılamayan üstün zekâlılarla ilgili batı kaynaklı araştırmalar bu eğitimin sonuçları hakkında bilgi verici niteliktedir. Bir araştırmada hızlandırma eğitimine katılanların 70'inin bundan memnun olduğunu, \%13'ünün eğitimin daha çok hızlandırılmış olmasını arzu ettiğini, \%5'lik bir bölümün de hızlandırma programına katılmaktan memnun olmadığını bildirilmiştir (Lubinski, D. ve Diğerleri, 2001). Hızlandırılmış eğitime katılanların benlik saygısı, kendine güven, olumlu sosyal ilişkiler kurma, ders dışı etkinliklere katılma ve yaşam doyumu konusunda hızlandırılmış eğitime katılmayanlara göre ya onlarla eşit düzeydedir veya onlardan daha iyi düzeydedir (Steenbergen-Hu ve Diğerleri). Hızlandırılmış eğitimden geçen öğrencilerle, katılmayan diğer öğrencilere göre eğitimin ileri seviyelerine daha çok ulaşmak istemektedirler (Southern, W. ve Diğerleri, 2004).

Üstün zekâlı öğrenciler sosyal ve duygusal olarak akranlarından daha olgun olma eğilimindedirler. Birçok üstün zekâlı öğrenci için hızlandırma eğitimi, bu eğitimi almayanlara göre daha çok kişisel olgunluk kazandırmaktadır (Robinson, M.N. 2004). Hızlandırılmış ve hızlandırılmamış eğitime katılan üstün zekâlı öğrencilerin on yıllık takip çalışması sonucunda hem katılanların, hem de katılmayanların etkileyici akademik başarılar elde ettikleri, okuldan ve kendilerinden yüksek düzeyde kişisel memnuniyet duydukları belirtilmektedir (Swiated, M. ve Benbow, C. 1991). Araştırma bulguları hızlandırma eğitimine katılmış olan üstün zekâlıların bundan olumsuz etkilendiğine dair bir bulgu sunmamaktadır. Çeşitli araştırmalar üstün zekâlıların hızlandırılmış eğitimden olumlu yararlandığını açıkca ortaya koymaktadır. Üstün zekâlılık çok önemli bir insan sermayesidir. Dünyadaki bilimsel ve teknolojik gelişmelerin çoğunu üstün zekâlı insanlara borçluyuz. Üstün zekâlı bireyler sayıları az bir beşeri kaynaktır (Bilgili, A.E. 2004). Üstün zekâlıların tanılanması ve onlardan insanlık adına yararlanılması için programlar hazırlamak ülkenin yararına olan bir zorunluluktur.

\section{Üstün zekâlıların hızlandırılmış eğitimden yararlanması için uygulanabilir öneriler}

Çocuk ve Medeniyet 2020/2
1. İlkokul birinci sınıftaki ilk kayıtlarda üstün özellikler taşıyan çocuklar velilerinin talebi ile 60 aylıktan itibaren birinci sınıfa kayıt 
olabilmektedir. Bu konudaki Milli Eğitim Mevzuatının il ve ilçe teşkilatlarına, özel ve resmi anaokulu ve ilkokullara bildirilerek bu yolla velilerin bilgilendirilmesi, üstün zekâlılık belirtilerini gösteren erken gelişmiş çocukların erken kayıt imkanından daha çok yararlandırılmasını sağlar.

2. İlkokuldaki sınıf yükseltme uygulaması bir defa değil iki defa uygulanabilmelidir. BİLSEM'ler tarafından tanılanmış, zekâ bölümü en az 145 olan öğrenciler ikinci yükseltme sınavına alınabilirler.

3. Sınıf yükseltme uygulaması ortaokul öğrencileri için de bir kez yapılmalıdır. Aynı şekilde BILLSEM'ler tarafından tanılanmış ve en az 145 zekâ puanına sahip olanlar sınıf yükseltme sınavına bir kez girebilmelidir.

4. Sınavla öğrenci alan Anadolu Liseleri, Anadolu İmam Hatip Liseleri, Anadolu Teknik Liseleri, Fen Liseleri, Sosyal Bilimler Liseleri, Güzel Sanatlar ve Spor Liselerindeki zekâ bölümleri en az 145 olan ve ilk bine giren öğrencilerin her bölgede ayrı ayrı okullarda toplanması, bu okulların ders programlarının kredili sisteme göre düzenlenerek öğrencilerin okulu dört yıldan önce bitirebilmesine imkan tanınması sağlanmalıdır.

5. İstanbul Çamlıca'da 2017 yılında kurulan Araştırma, Geliştirme, Eğitim ve Uygulama Merkezi ortaokul ve lisesi olan ARGEM, BİLSEM tarafından tanılanmış üstün zekâlı çocukların özel eğitimi için kurulmuş örnek bir okuldur. Bu örnek okulun Ankara, İzmir, Adana, Diyarbakır, Erzurum ve Trabzon gibi merkezlerde de açılması ve programlarının kredili sisteme göre düzenlenerek, öğrencilerinin eğitimlerini daha kısa sürede tamamlamalarına imkan sağlamak mümkündür.

6. Kredili sistemle okuyan üstün zekâlı öğrencilerin uzaktan eğitim yoluyla eğitim sürelerini kısaltmak mümkündür. Hafta sonları ve tatil zamanlarında uzaktan eğitim alıp, eksik derslerini tamamlayabilirler (Cirik, M. 2016).

7. Lisede örgün eğitimine devam edemeyenler için başlatılan bir uygulama olan Açık Lise kolayca sınıf geçme esasından ders geçme esasına göre düzenlenip, kredili sisteme dönüştürülebilir. Lisedeki eğitimi seviyelerine göre düşük bulan üstün zekâlı öğrenciler kredili sistem uygulaması ile liseyi öğrenme hızlarına uygun bir şekilde vaktinden önce tamamlayabilirler. yapma, yandal yapma, ilgi ve yeteneklerine uygun farklı dersler alma gibi 


\title{
seçenekleri vardır. Üniversite öğrencileri bu imkanların yanında değişik sertifika programlarına devam ederek kendilerini gerçekleştirme imkanına sahiptirler.
}

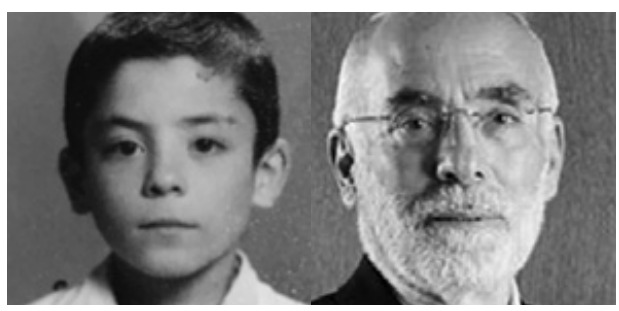

\author{
Adnan Kulaksızoğlu
}

\section{Kaynakça}

Akarsu, Füsun. "Üstün Yetenekliler” (2004) Üstün Yetenekli Çocuklar Seçilmiș Makaleler Kitabı. M.R. Șirin, A. Kulaksızoḡlu, A.E. Bilgili, Cocuk Vakfı Yayınları, İstanbul.

Ayșegül, Ataman. “Üstün Zekalı ve Üstün Yetenekli Cocuklar” (2004) Üstün Yetenekli Cocuklar Seçilmiş Makaleler Kitabı. M.R. Șirin, A. Kulaksızoḡlu, A.E. Bilgili, Cocuk Vakfı Yayınları, İstanbul.

Ayșegül, Ataman. “Geleceḡin Mimarları" Üstün Yetenekliler Sempozyumu. Namık Kemal Üniversitesi, Saḡlık Hizmetleri Meslek Yüksek Okulu, 27.04.2012.

Bakioḡlu, A., Levent, F. “Üstün Yeteneklilerin Eḡitiminde Türkiye İçin Öneriler” Üstün Yetenekli Araștırma Dergisi, 2013, 1(1) ss.31-44.

Bilgili, A. E. "Üstün Yetenekli Çocukların Eḡitimi Sorunu, Sosyal Sorumluluk Yaklașımı” (2004) Üstün Yetenekli Cocuklar Seçilmiș Makaleler Kitabı. M.R. Șirin, A. Kulaksızoḡlu, A.E. Bilgili, Cocuk Vakfı Yayınları, İstanbul.

Caḡlar, D. “Üstün Zekalı Cocukların Özellikleri” (2004)Üstün Yetenekli Cocuklar Seçilmiș Makaleler Kitabı. M.R. Șirin, A. Kulaksızoḡlu, A.E. Bilgili, Cocuk Vakfı Yayınları, İstanbul.

Chapman, Chiristine. “A Smoother Acceleration” The Science Teacher, Washington, Vol.76, Iss.3, (March, 2009) :42-45).

Cırık, Mevlut. “Uzaktan Eḡitimin Üstün Zekalı Öğrencilerin Eḡitimindeki Yeri” Açıköḡretim Uygulamaları ve Araștırmaları Dergisi, AUAd 2016, Cilt 2, Sayı 3,ss.170-187.

Davaslıgil, Ümit. “Üstün Zekalı Çocukların Eggitimi” (2004) Üstün Yetenekli Çocuklar Seçilmiș Makaleler Kitabı. M.R. Șirin, A. Kulaksızoḡlu, A.E. Bilgili, Cocuk Vakfı Yayınları, İstanbul.

Kanlı, Esra. “Üstün Zekalı ve Yeteneklilerin Alan Eḡitiminde Hızlandırma” Hasan Ali Yücel Eğitim Fakültesi Dergisi, Sayı:16 (2011-2) ss.85-104.

Lubinski, D.,Webb, R.M., Morelock, M.J., Benbow, C.P. “Top 1 in 10.000: A Ten Year Follow-up of the Profoundly Gifted” Journal of Applied Psychology, (2001), 86, 718-729.

“Milli Ēgitim Bakanlığı Okul Öncesi Eḡitim ve İlköḡretim Kurumları Yönetmeliḡi” Resmi Gazete, 26 Temmuz 2014, Cumartesi, Sayl: 29072. mevzuat.meb.gov.tr/dosyalar/1703.pdf

Robinson, Nancy M. (2004) "Effects of Academic Acceleration on the Social-Emotional Status of Gifted Students” A Nation Deceived: How School Hold Back America's Brightest Students, Volume II (Ed. Nicolas Colangelo and Odhers) The Templeton National Report on Acceleration Published at The University of lowa, lowa City, lowa

Sak, U. (Nisan 2010) “Üstün Zekalılar, Özellikleri, Tanılamaları, Eḡitimleri” Maya Akademi Yayınevi Ankara

Çocuk ve Medeniyet 2020/2
Southern, W. Thomas, ve Dones, D. Eric. (2004) “Types of Acceleration: Dimensions and Issues" A Nation Deceived: How School Hold Back America's Brightest Students, Volume II (Ed. NicolasColangelo and Diḡerleri) The Templeton National Report on Acceleration. Published at The University of lowa, lowa City, lowa 
Steenbergen-Hu, Saiying ve Moon, M. Sidney "The Effect of Acceleration on High Ability Learners, A Meta Analysis" Gifted Quarterly, xx(x)1-15 http://gcq. Sagepub.com

Swiated, Ann Mary ve Benbow Rerson Camilla. "Ten Year Longitutional Follup-up of Ability-hMatched Accelerated and Unaccelerated Gifted Students” Journal of Educational Psychology, 1991, Vol. 83, No.4, pp.528-538.

Tortop, Hasan Said. “Olaḡanüstü Üstün Yeteneklilerin Eḡitim Sürecinde Radikal Hızlandırma ve Türkiye'nin Durumu” Yükseköğretim ve Bilim Dergisi, Cilt 2, Sayı 2, Aḡustos 2012, ss. 106-113 